\title{
Integration Policies and Immigrants' Labor Market Outcomes in Europe
}

\author{
Irena Kogan
}

University of Mannheim

Abstract: This article assesses whether two integration policy measures (labor market training and counseling) reach the immigrants who need them and whether these policies improve immigrants' labor market situations. We first examine the comprehensiveness of integration policies by linking Migration Integration Policy Index scores of immigrants' labor market mobility with levels of immigrant participation in labor market training and counseling in 15 European countries. We find that provision with labor market training does not entirely correspond to policy intentions, whereas labor market counseling more closely achieves policies' proclaimed aims. Second, we carry out propensity score matching analysis to estimate the effectiveness of immigrants' integration policies. We find that labor market training and counseling do not improve immigrants' employability or job status in three of the four analyzed countries, which lends weak support to the productivity skills argument, emphasizing instead the validity of the signaling and selection perspectives.

Keywords: integration policy; immigrant integration; comparative study; labor market outcomes; quantitative research

Citation: Kogan, Irena. 2016. "Integration Policies and Immigrants' Labor Market Outcomes in Europe." Sociological Science 3: 335-358.

Received: January 16, 2016

Accepted: February 19, 2016

Published: June 3, 2016

Editor(s): Jesper Sørensen, Olav Sorenson

D0I: $10.15195 / \mathrm{v3} . \mathrm{a} 16$

Copyright: (C) 2016 The Author(s). This open-access article has been published under a Creative Commons Attribution License, which allows unrestricted use, distribution and reproduction, in any form, as long as the original author and source have been credited. @()
$\mathrm{M}$ OTIVATED by the surge in international migration, European countries are increasingly concerned about their capacity to integrate newcomers and adapt to increasing ethnic and religious diversity. By adjusting their admission policies, Western countries attempt to strike a balance between their humanitarian responsibilities and their economic burdens and needs. At the same time, countries undertake considerable efforts to help newcomers transition into the host countries' labor market and society. Officials use various methods-such as language courses, professional training and retraining, and recognition of qualifications from immigrants' countries of origin or labor market counseling - to help facilitate immigrant settlement and integration (Reitz 2003). Yet there are frequent concerns that newcomers' potential and human capital resources are wasted when they fail to adequately integrate into host country labor markets, face long-term unemployment, or work in jobs for which they are overqualified (Kogan 2006, 2007; van Tubergen, Maas, and Flap 2004; Fleischmann and Dronkers 2010). This apparent contradiction between host countries' increasing integration efforts and immigrants' persistent labor market difficulties suggests that integration policies may not substantially contribute to immigrants' labor market integration. This article explores whether this is the case by examining both the comprehensiveness of these policies' coverage and their effectiveness, that is, whether immigrant integration policies in Europe meet the needs of a substantial number of newcomers and produce more favorable labor market outcomes. 
This study is embedded in two types of literature. One is related to the measurement of policy dimensions. Without disregarding any important research on the measurement of various policies (see, e.g., Ruhs [2011] and Goodman [2010] with regard to immigration and asylum policies or Koopmans, Michalowski, and Waibel [2012] and Janoski [2010] with respect to naturalization policies), we will rely on a widely known Migration Integration Policy Index (MIPEX). MIPEX measures the extent to which non-citizens and ethnic minorities are legally entitled to equal rights and responsibilities in a host country. The 2007 version of the MIPEX ${ }^{1}$ is based on more than 140 indicators collected via expert surveys covering 28 countries in Europe and North America (Niessen, Huddleston, and Citron 2007; Huddelston et al. 2011). The index assesses and ranks public laws, policies, and research on several topics, including labor market mobility, family reunion, education, ${ }^{2}$ political participation, long-term residence, access to nationality, and anti-discrimination. ${ }^{3}$ The first objective of the current study will be to juxtapose MIPEX scores on labor market mobility with the representative European Union Labour Force Survey (EULFS) data capturing recent immigrants' participation in the selected integration programs to assess the comprehensiveness of immigration policy coverage.

The second type of research literature evaluates the effectiveness of immigrant integration policies. Several large-scale studies examine at the macro level whether immigrants' socioeconomic standing is related to host countries' immigration and integration policies (e.g., Pichler 2011; Hadjar and Backes 2013). There are also a number of smaller-scale country-specific evaluation studies, predominantly conducted by economists, that estimate the specific effects of various integration programs (e.g., Clausen et al. 2009; Thomsen and Walter 2010). The first group of studies in this second strand of research predicts immigrants' individual behavior based on host and/or sending countries' institutional and policy characteristics. The major problem of this research is related to difficulties in identifying the causal effects of the policies. The second group of researchers estimates the causal effects of integration measures primarily by analyzing the individual-level impact of specific integration programs, often in (quasi-)experimental settings. The findings of such studies are often restricted to a specific integration measure and have limited generalizability.

This article aims to bridge these literatures. We use representative data for a large number of countries to assess two central indicators of successful policies: (1) whether selected immigrants' integration policy measures reach the immigrants who need them and (2) whether these policies improve immigrants' labor market situations.

The article is structured as follows. First, we summarize the findings of the existing research that examines the associations between countries' integration policies and immigrants' integration. We also address the major conclusions from various evaluation studies that relate to the role of certain integration measures in immigrants' integration processes. On the basis of the microtheoretical foundations, we then discuss possible scenarios for policy effects and confront them with the data from the 2008 EULFS ad hoc module on migrants' labor market situations. We then present our major findings and discuss them in light of the theories and 
the existing research in the field. The article concludes with theoretical and policy reflections and identifies major directions for further research.

\section{State-of-the-Art Research}

Research focusing on immigrant policy interventions can broadly be divided into two strands. First, large-scale studies examine at the macro level whether immigrants' socioeconomic situation is related to host countries' integration policies. MIPEX results in relation to immigrants' labor market situations remain equivocal. Aleksynska and Tritah's (2013) study is, to the best of our knowledge, the only one that reports a significant positive association between MIPEX and objective labor market outcomes. According to the authors, a match between jobs and qualifications among the foreign born is positively associated with full and immediate access to the labor market. Other research finds no significant association between MIPEX and other outcomes of immigrants' labor market integration: unemployment propensity (Cebolla Boado and Finotelli 2011; Pichler 2011), labor force participation (Cebolla Boado and Finotelli 2015; Pichler 2011), occupational prestige (Corrigan 2015), and occupational class (Pichler 2011). Hadjar and Backes (2013) report a smaller gap in subjective well-being between immigrants and natives in countries with higher MIPEX scores.

Summarizing multilevel studies that apply MIPEX, Bilgili, Huddleston, and Joki (2015) also ascertain that evidence of a systematic link between general integration policies and immigrants' labor market inclusion is inconclusive. The authors maintain that this does not mean the policies do not matter, but rather that they are not properly implemented, targeted, or effective across countries. Bilgili et al. point out possible challenges in using MIPEX to measure policy effects. A mismatch between the policies captured by the MIPEX's specific and overall scores and the analyzed integration outcomes might partially explain the lack of significant associations between the two. When overall MIPEX scores are used as a predictor, a major assumption is that all types of policies as a whole are related to an analyzed outcome. When such a relationship is not theoretically or empirically established, a lack of correlation between the overall MIPEX score and labor market outcomes might be a consequence. Bilgili et al. also identify a mismatch between the targets of the specific integration policies and the individuals who are analyzed in empirical settings. They assert that researchers insufficiently take into account the heterogeneous effects of policies on various immigrant population groups: for example, firstand second-generation immigrants, immigrants from within versus outside the EU, and those immigrating for various reasons and with different settlement intentions.

The second strand of research comprises smaller-scale, country-specific evaluation studies of various integration programs, often in the Nordic countries, Germany, or Israel. For example, Åslund and Johansson (2006) report that immigrant workplace introduction programs in Sweden increase transitions from unemployment to work schemes and improve their participants' later employment chances. Clausen et al. (2009) analyze the effects of active labor market programs (ALMPs) on the hazard rate of entry into regular employment for new immigrants to Denmark. Their results are mixed but indicate that participants of language courses and wage 
subsidy programs enter into regular employment significantly more often than nonparticipants with similar qualifications and educational backgrounds. Sarvimäki and Hämäläinen (2011) state that integration programs for immigrants to Finland significantly improve their employment opportunities and reduce their dependence on social benefits. Analyzing immigrants from the former Soviet Union arriving in Israel in the 1990s, Cohen and Eckstein (2008) and Cohen-Goldner and Eckstein (2010) find that training has a positive effect on wages, which increases over time. Aldashev, Thomsen, and Walter (2010) report positive effects for training programs in Germany, which were stronger for women without a migration background than for those with a migration background. Thomsen, Walter, and Aldashev (2013) ascertain that, in Germany, courses that provide occupational skills and prepare participants for aptitude tests have a positive effect on both immigrants and natives (with only a slight difference between the two groups), whereas job search training and multitargeted programs prove to be largely ineffective.

In his summary of the existing evaluation research, Rinne (2013) stresses that out of immigrant introduction programs, language training, ALMP, and antidiscrimination policies, programs that are closely linked to the labor market (e.g., specific types of ALMP) appear to be most effective. In a meta-analysis of ALMP for immigrants to Europe, Butschek and Walter (2014) scrutinize four types of ALMPs: classroom or on-the-job training, job search assistance, and both subsidized privateand public-sector employment. Based on 33 empirical studies from 7 countries (Denmark, Finland, Norway, Sweden, Germany, the Netherlands, and Switzerland), the authors conclude that subsidized employment in the private sector exerts a significant positive effect on immigrants' labor market outcomes, which echoes Rinne's (2013) major finding. The bad news, however, is that immigrants are underrepresented in this type of program and are more likely to be found in training programs and public-sector employment, which seems to be less effective.

The overall evidence of the effects of immigrant integration policies on immigrants' labor market outcomes is inconclusive. This is common for both macroand multilevel studies, as well as for policy evaluation studies, although the latter find that some active labor market policies have positive effects. The next section discusses why any policy effects are to be expected in the first place.

\section{Microtheoretical Foundation and Expected Outcomes}

The empirical evidence shows that upon arrival in a new country, immigrants often slip down the occupational ladder and earn lower wages than natives with similar socioeconomic characteristics (Chiswick 1978, 1979; Borjas 1990, 1994). One obvious explanation is that resources such as foreign educational qualifications, social connections, or cultural knowledge are not fully transferable to the new setting (Friedberg 2000; Kogan et al. 2011). Over time, as immigrants become familiar with the local labor market and language, they adjust their resources to the new setting and eventually reach a similar labor market standing as natives with comparable credentials. The speed of the integration process depends, among other factors, on what type of integration programs the host country offers. The current study scrutinizes two such programs: training and labor market counseling. 
Productive skills and signaling perspectives are two related, yet distinct, theoretical approaches to explaining why the preceding policy interventions should affect immigrants' integration. According to human capital theory (Becker 1964), formal education and training provide relevant general and occupational skills that can be productively used in the workplace. The longer people stay in education, the higher their subsequent earning potential (Mincer 1974). Human capital specificity is particularly relevant for immigrant populations, which implies that host country education/training (including language education) should increase immigrant productivity. Although not strictly a source of productive skills, social capital might also contribute to the better utilization of human capital via informational advantages, a more strategic job search, and the availability of successful role models (Kalter and Kogan 2014).

The second theoretical approach conceives credentials received within education or training systems as institutionalized signals of job-related competence that could also encompass information about potential productivity (Spence 1973; Stiglitz 1975). Participation in training, for example, not only reflects existing skills, but also signals characteristics related to employability that are not directly acquired through schooling, such as general scholastic ability, perseverance, motivation, trainability, and obedience. Signals are not always positive: they might lead to stigmatization if they indicate adverse selection, for example, for participants in integration measures that target particularly disadvantaged groups. Because signals are normally used in candidate screening to overcome uncertainty resulting from imperfect information about workers' performance, immigrants without any reliable signals are likely to be penalized. This is due to informational discrimination (Cain 1986), which is related to employers' uncertainty about immigrants' productivity, trainability, or other characteristics relevant to job performance.

On the basis of these arguments, it seems obvious that participation in training programs should help immigrants succeed in the labor market. From the human capital perspective, host country investment in human capital should make immigrants more productive, particularly if the expenditure relates to professional knowledge and host country-specific skills that make newcomers more attractive to prospective employers. Training is also expected to expand immigrants' social networks and hence ease their navigation within the host country labor market. From the signaling perspective, an immigrant with host country training signals to employers the immigrant's perseverance and trainability, which decreases the costs of uncertainty in the recruitment process-assuming that employers notice (and positively evaluate) host country training.

Although labor market counseling might also instill productivity-related skills, such support should be considered a source of social capital for recent newcomers; these services provide labor market-related information and help broaden immigrants' ties to the native population, which might encourage their assimilation into mainstream institutions (Wiley 1970; Portes and Rumbaut 2001). Yet immigrants who have received labor market counseling might carry a negative signal and be stigmatized due to their perceived (or actual) negative (self-)selection.

The selection issue is an obvious challenge when gauging the effectiveness of integration policy instruments. Do policy interventions have a causal effect, or 
are effects driven by the self-selection of individuals with specific characteristics that are likely to correlate with the observed outcomes of the intervention policy measures? Normally, individuals are not randomly assigned to training courses or labor market counseling but rather are a self-selected group. Such selection can be positive if immigrants with characteristics that are more favorable to the labor market decide (or are persuaded) to take part in an integration measure. With regard to labor market training, this would imply that more persistent, motivated, and hardworking individuals start and persevere to the end of the training course. Yet these favorable unobserved (in the data) characteristics might be the ones that employers observe during a job interview that lead to a job offer or better employment conditions. Reliance on labor market counseling, by contrast, might have negative connotations that individuals are not confident or resourceful enough to succeed in the labor market on their own.

All this leads to the following possibilities regarding the impact of integration policies on labor market success, defined in this study as immigrants' more favorable labor market allocation. After taking selection on observables into account, we can expect the following scenarios:

- Scenario 1: Integration policies have a positive effect if they (1) are effective (i.e., they improve immigrants' country-specific human, cultural, and social capital) and/or (2) convey a positive signal to prospective employers (which is also adequately perceived by employers) and/or (3) cater to participants with positive characteristics that are observable to employers but remain unobservable to researchers.

- Scenario 2: Integration policies have a zero or negative effect if (1) they are ineffective and/or (2) participants are stigmatized by employers and/or (3) participants are negatively selected based on traits that are observable to employers but not to researchers.

A zero effect can in principle also mean that an effective policy intervention might be canceled due to the stigmatization or negative selection of program participants by employers. However, this is rather unlikely, because the three afore mentioned conditions are not unrelated. If policies are effective, it is unlikely that they carry a negative signal. If participants of the programs are known or perceived to be negatively selected, a positive signal is also quite unlikely. A single combination of conditions that we cannot rule out is when effective policies cater to negatively selected-in terms of unobserved characteristics-participants once their observed characteristics are taken into account. Because negative selection is more likely among recipients of labor market counseling, zero effects for this treatment (as a result of adverse forces of skill accumulation and self-selection mechanisms) are more plausible.

\section{Data and Methodology}

Our empirical analyses are conducted using microlevel data from the 2008 EULFS ad hoc module on migrants' labor market situation. The main advantages of this 
data set are its broad coverage and inclusion of a range of variables pertaining to immigrant integration policy dimensions at the individual level. This module is an addition to a regular EULFS questionnaire that includes a large set of variables related to the sociodemographic and labor market situation of the EU population. The ad hoc module data capture information on immigrant populations since the end of the Second World War, but this study focuses on immigrants who arrived in the 10 years preceding the survey because the questions related to integration measures were asked of these most recent immigrants. Our analyses are further restricted to immigrants of working age (20-64 years). Our descriptive analysis covers Austria, Belgium, Luxembourg, Germany, Spain, France, Greece, Ireland, Italy, the Netherlands, Norway, Sweden, the United Kingdom, Cyprus, and Portugal, while we use a subset of these countries (the Netherlands, Italy, the United Kingdom and Ireland) to test our hypotheses due to the sample sizes. ${ }^{4}$ This subset of countries is a fair representation of various immigrant integration approaches, as signified by MIPEX 2007 scores (for labor market mobility) ranging from 85 in the Netherlands to 42 in Ireland (for the discussion of country scores, see later).

The current study scrutinizes two integration policy measures: (1) participation in labor market training and (2) participation in labor market counseling (contact with an adviser for job guidance/counseling or job search assistance). To estimate whether these programs have any effect on immigrants' labor market attainment, we apply a propensity score matching (PSM) analysis. In recent years, this method has received increasing scholarly attention in the field of sociology (for the explanation of its methodology, see Morgan and Harding [2006], Winship and Morgan [1999]; for its empirical applications, see Brand and Halaby [2006], Harding [2003], and Kogan, Matković, and Gebel [2013]; for an application in migration research, see Kogan [2012]). This approach allows us to analytically distinguish between self-selection into the treatment (i.e., integration measures in our case) and the subsequently observed labor market outcomes (for a description of outcomes, see later).

To achieve this goal, in the first step of the analysis, we run a separate probit regression model for each of the four countries to estimate an individual probability (propensity score) of receiving labor market counseling or participating in labor market training $(D=1)$ as opposed to non-participation $(D=0)$ (hence two probit models per country), given observable individual characteristics $X$ (Rosenbaum and Rubin 1985). In the second step, for each person participating in labor market training or receiving labor market counseling, we create a counterfactual: a statistical twin-propensity scores $P(D=1 \mid X)$-who abstained from a given integration measure (i.e., an individual with similar characteristics who was eligible to participate in the program but did not). A "causal" effect is defined as the difference in the outcome variable for members of the treatment group and the respective control group. More specifically, the difference in the unemployment propensity and the occupational status of jobs observed between the two groups represents an average treatment effect on the treated (ATT), which measures the average penalty or advantage in terms of employment chances and job occupational status (see following definitions) for those who participated in integration programs compared to those who could have participated but did not. Treatment effects are identified under the conditional independence assumption, which means that, dependent on 
observable control variables, all outcome-relevant differences between those who participated in training and counseling and those who did not are balanced, and that the only remaining difference is due to participation in counseling or training. A common support condition guarantees that only persons with suitable control cases are considered (see supplementary Tables A.1 and A.2 for the information on total number of cases and number of cases with common support ${ }^{5}$ ). While relying on a similar assumption of selection on observables as when carrying out a conventional regression analysis (Winship and Morgan 1999), matching guarantees a more appropriate weighting of covariates and better deals with mis-specification errors thanks to its nonparametric outcome estimation.

The study examines two labor market outcomes: unemployment propensity and jobs' occupational status measured against the International Socio-Economic Index of Occupational Status (ISEI) (Ganzeboom, de Graaf, and Treiman 1992) based on the International Standard Classification of Occupations (ISCO-88). Both outcomes are measured in 2008, after the treatment. In the unemployment propensity analysis, we restrict our sample to economically active individuals, whereas in the occupational status models, analyses are restricted to gainfully employed individuals.

We take into account a number of observable individual characteristics when estimating propensity scores. The strictly exogenous variables include immigrants' ethnic origin: we differentiate between immigrants coming from new EU member states, non-EU Europe, countries of the Middle East and Northern Africa (MENA), other African countries, Asian countries (for the United Kingdom we further differentiate between South Asia and East and Southeast Asia), North and Latin America, and the rest of the world. Immigrants from the EU-15 and European Free Trade Association (EFTA) countries serve as a reference category. ${ }^{6}$ Native-born populations are excluded from the analyses. Other covariates include sociodemographic and migration-related variables such as gender, age at migration, year of migration, and legal status at migration (asylum seekers, family reunification/formation, other, and employment-related, the latter a reference category). We also include a variable that indicates whether immigrants had children aged under three at migration or 2 years following migration. ${ }^{7}$ Education is measured in three categories: low secondary and below (categories 1-2 on the International Standard Classification of Education, abbreviated as ISCED), upper secondary (ISCED 3-4), and tertiary (ISCED 5-6). Other variables related to immigrants' integration efforts that pertain roughly to the timing of migration include accreditation of educational credentials (education recognized, education unsuccessfully recognized, host country education, no need for recognition, not recognized), immigrants' participation in language courses and labor market training programs (when modeling labor market counseling) or labor market counseling (when modeling training participation). Finally, to capture as many unobserved individual characteristics as possible, we included variables measured in the survey that are unlikely to be influenced by participation in integration programs: ${ }^{8}$ legal residence status (temporary vs. permanent permits, naturalization) and region of residence (captured by the available regional classification for each country). Finally, to account for immigrants' host country knowledge proficiency at the time of migration, we include a variable that indicates whether immigrants feel they have a deficit in the official host country language. This variable is measured 
in 2008, but if immigrants were still experiencing problems with the host country language when the survey was conducted, these would have been more serious at the time of migration.

Before we test effects of labor market training and counseling, the following analyses explore several related aspects. First, to determine the comprehensiveness of integration measures, the next section explores whether policy coverage corresponds to the policy intentions as measured by the MIPEX 2007 labor market mobility score and its components (access to general and targeted support, access to targeted support among third-country immigrants). The degree of selectivity among participants in immigrant integration programs is then assessed based on the first step of the PSM-probit regression models of program participation for the sample of economically active immigrants. Finally, the results of the second step of PSM analysis are presented to assess the effectiveness of immigrant integration policy interventions.

\section{Immigrant Integration Program Coverage}

An optimal scenario of immigrants' labor market integration ${ }^{9}$ includes their unrestricted rights to access jobs in the private and public sectors or become selfemployed, the opportunity to have their qualifications from abroad recognized, and the ability to improve their skills through training and language instruction. In an ideal integration environment, job advisors are expected to help immigrants canalize their skills and assist in their job search. The MIPEX monitors the degree to which countries' policies correspond to the ideal situation by assigning them a score from 0 to 100. It captures labor market mobility, which is comprised of subelements including access to the labor market, access to general and targeted support, and insurance of equal workers' rights. General and targeted support includes policy tools that facilitate the recognition of skills and qualifications from outside the EU and measures to further integrate immigrants into the labor market, including the promotion of vocational training and language acquisition and support in accessing public employment services. Targeted support measures comprise those designed to integrate third-country nationals.

Countries vary with regard to their MIPEX 2007 scores on the composite and special dimensions; Sweden scores the highest (100) and Cyprus the lowest (21) on both. Austria and Ireland score higher on the composite labor market mobility, but lower on the general and targeted support dimension (see Figures 1-3 and 4-6). Figures 3 and 6 indicate that targeted policies are the least developed area of host countries' integration policies. Of the 13 countries analyzed, ${ }^{10}$ seven score below 40 on the MIPEX scale. This section explores whether policies related to the provision of labor market training and counseling are properly implemented in European countries: that is, whether they exist on the books and also attract meaningful immigrant participation.

Figures 1-3 plot the proportion of immigrants in European countries that participated in labor market training in the first 2 years after immigration. This is correlated with countries' MIPEX 2007 composite scores of labor market mobility in Figure 1. With regard to labor market training, the correspondence between 


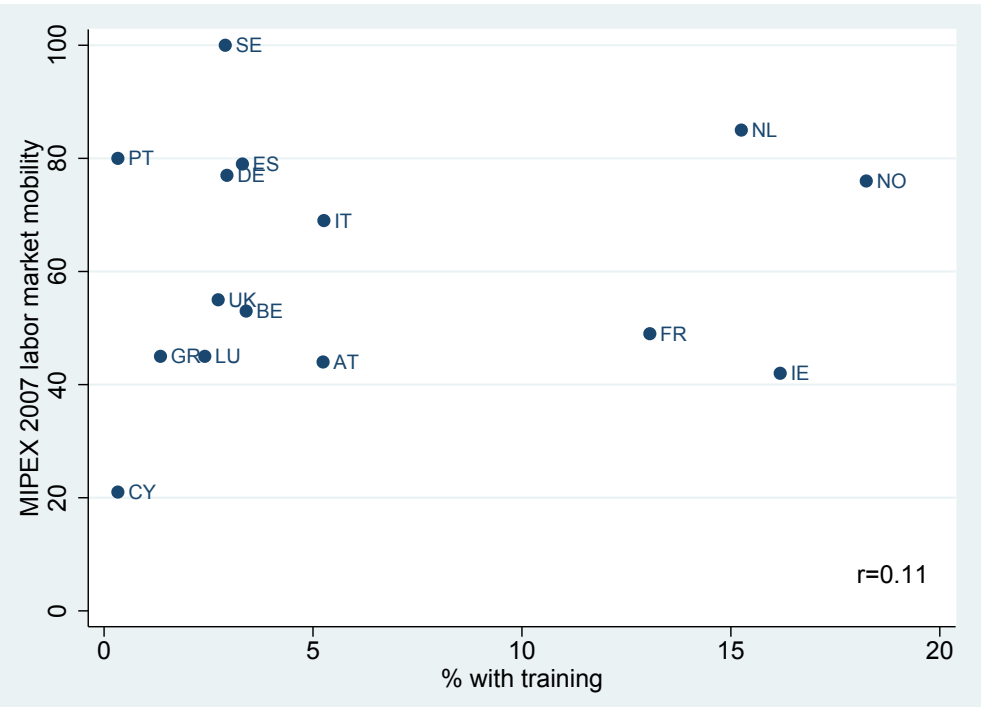

Figure 1: Proportion of immigrants who participated in training and countries' MIPEX of labor market mobility.

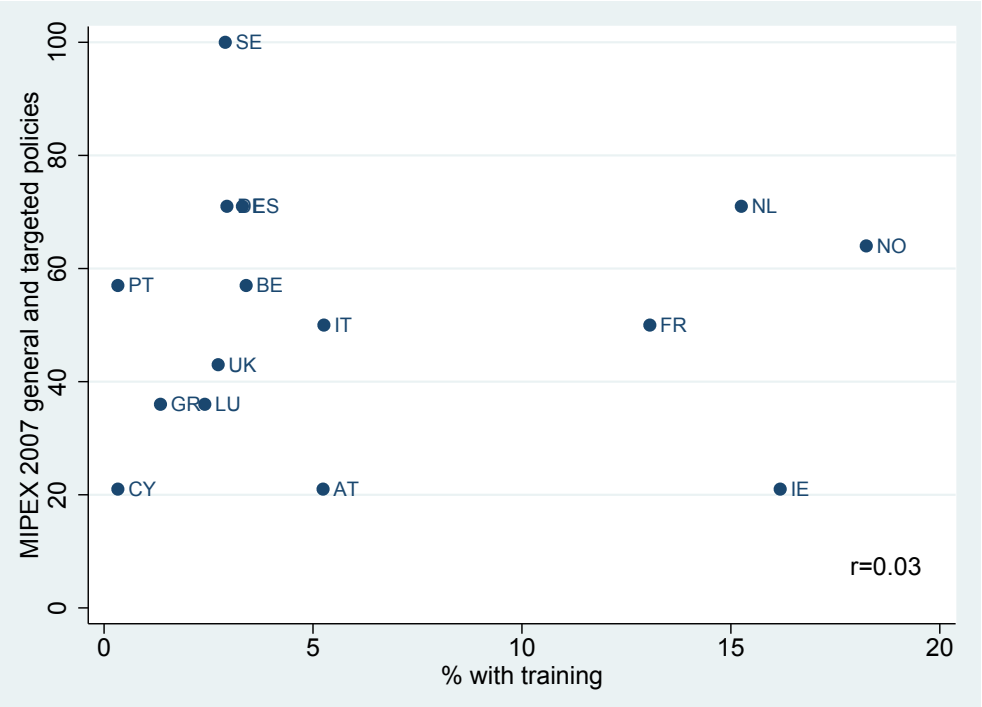

Figure 2: Proportion of immigrants who participated in training and countries' MIPEX of labor market mobility, access to general and targeted support.

"intentions" and "realities" is quite low. Sweden, Portugal, Spain, and Germany have high MIPEX scores, but a low level of training coverage. Figure 2 plots the proportion of immigrants in labor market training against the MIPEX special score on access to general and targeted policies. In this way, we try to narrow the scope of policies captured by MIPEX as closely as possible to the policy measure we analyze in the current study. The result is still not satisfactory: the correlation between the two is still rather low. Figure 3 compares the MIPEX score on targeted policies with 


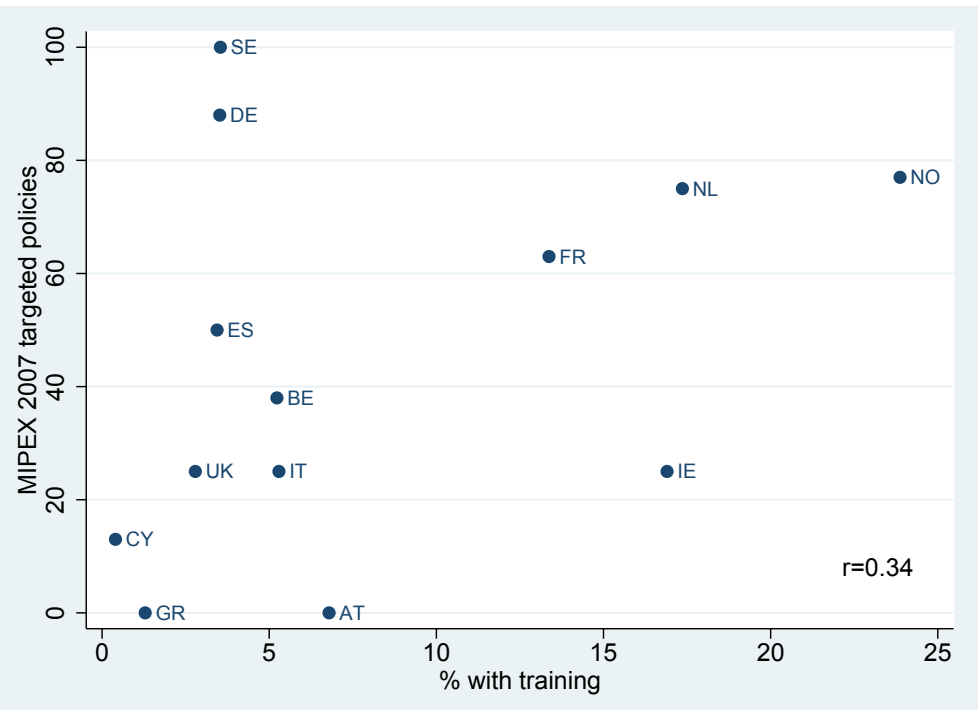

Figure 3: Proportion of third-country immigrants who participated in training and countries' MIPEX of labor market mobility, access to targeted support.

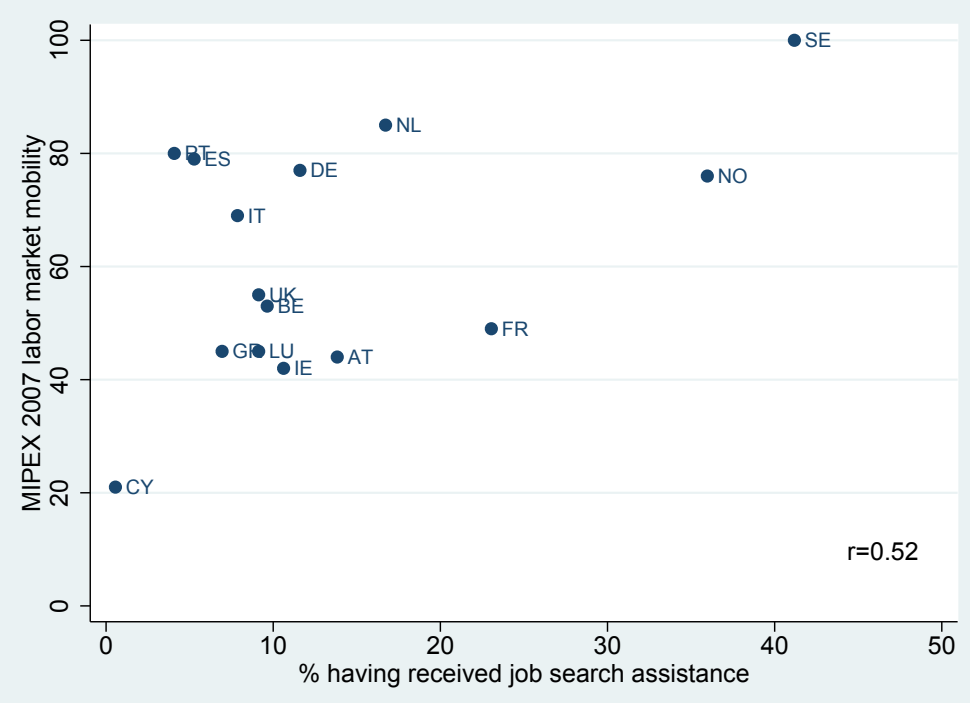

Figure 4: Proportion of immigrants who received labor market counseling and countries' MIPEX of labor market mobility.

the actual take-up of labor market training by third-country nationals targeted by these policies. This comparison improves the correlation coefficient substantially, which accords with Bilgili et al.'s (2015) recommendation to focus on the policy dimensions directly linked to the analyzed policies when working with the MIPEX.

In Figures 4- 6, the same exercise is conducted with regard to the receipt of labor market counseling among the immigrant population. Here we observe much stronger associations. The correlation is above 0.5 for both the MIPEX composite 


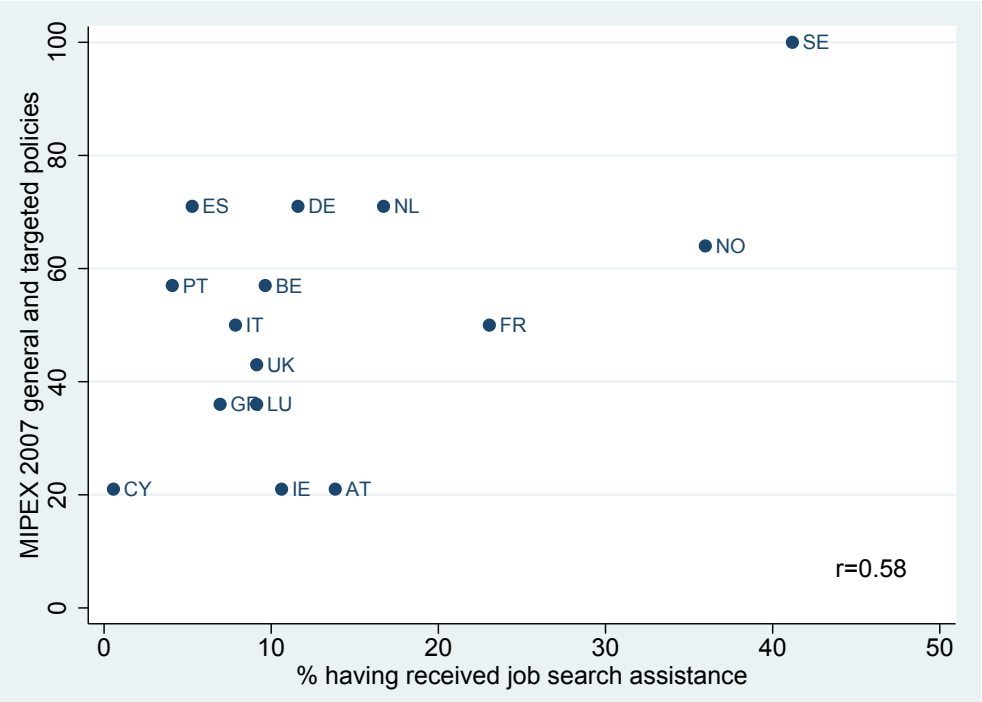

Figure 5: Proportion of immigrants who received labor market counseling and countries' MIPEX of labor market mobility, access to general and targeted support.

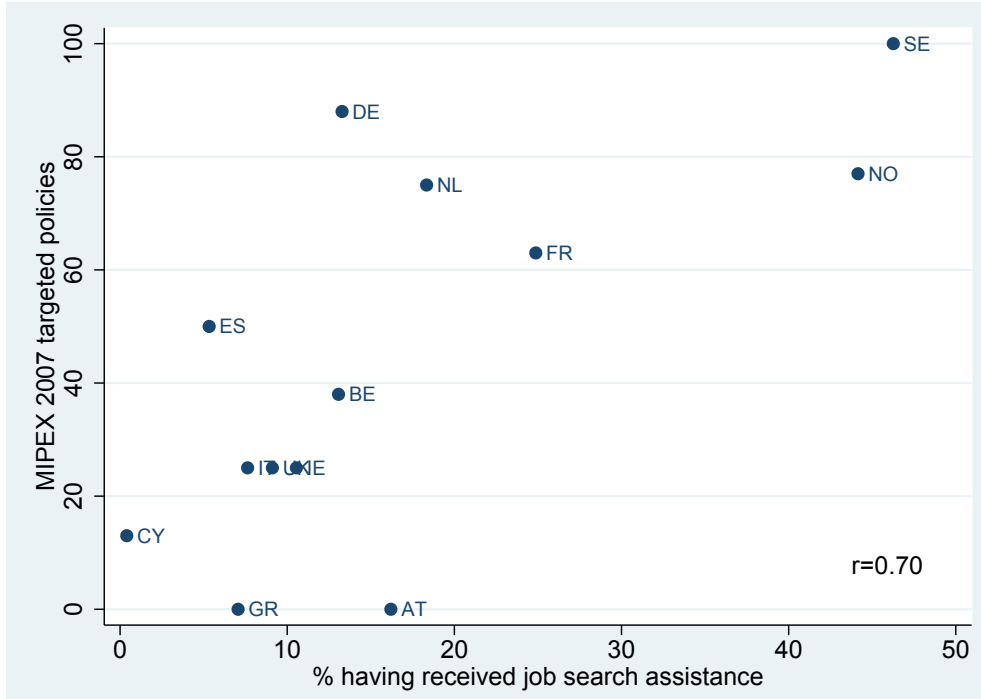

Figure 6: Proportion of third-country immigrants who received labor market counseling and countries' MIPEX of labor market mobility, access to targeted support. 
score of labor market mobility and access to general and targeted policies. When we reduce the analyzed population to third-country immigrants and the policy dimension to the targeted policies, the correlation coefficient is 0.7 . On the basis of the EULFS 2008 ad hoc module data, labor market counseling is more prevalent in European countries than labor market training participation. Our findings thus support Bilgili et al.'s (2015) conclusion that the lack of correlations between immigrant integration policies and labor market outcomes is partly because the policies might not be properly implemented in some countries. Although policy implementation with regard to coverage rates is an important indicator, a genuine test of policy effectiveness would be an assessment of the policies' "causal effect" in experimental (or at least quasi-experimental, as in this study) settings.

\section{Selectivity of Immigrant Integration Programs}

In the absence of true experimental data and due to the advantageous feature of high external validity, conducting PSM analysis with the representative EULFS ad hoc module data would be an appropriate alternative. The PSM intuitively approximates a randomization procedure of a true experiment as closely as possible and is hence a commonly applied method in evaluation research. As described in the methodological section, PSM is conducted in two steps. In the first step, we estimate the propensity to join a treatment group-in our case, participating in labor market training or receiving labor market assistance-as opposed to the control group. Although only a byproduct of the PSM, this analysis allows us to assess the extent of selectivity of participation in integration measures. ${ }^{11}$

For all countries in the subset, except Italy, individuals who received language tuition or labor market counseling were also more likely to have participated in labor market training (see Table 1). Apparently, integration offers tend to come as a package in these three countries. There is also a somewhat stronger tendency for higher educated immigrants to participate in labor market training, although the effects are not statistically significant in any of the analyzed countries apart from the United Kingdom. Other findings are even more country specific. Having acquired the highest level of education in the host country increases the odds of training participation in Ireland, decreases them in the United Kingdom, and is (in terms of statistical significance) unrelated to training in the rest of the countries in the subsample. Immigrants who are older when they migrate are more likely to participate in labor market training in the Netherlands, but not in the other countries analyzed, at least not in statistically significant terms. Finally, in the Netherlands, immigrants from non-EU European countries, MENA, and Asia are more likely to participate in labor market training than newcomers from EU15 or EFTA countries. A similar pattern of less privileged immigrants being channeled to labor market training is evident in Italy, but not in the United Kingdom or Ireland (see supplementary Table A.3).

Similar to labor market training participation, we also observe the clustering of integration measures with regard to the receipt of job search counseling (see Table 2): immigrants who completed a language tuition course or labor market training are more likely to have also received labor market counseling. Again, this holds true for 
Table 1: Selected Predictors of Participation in Training (Results of the Probit Regression from the PSM Analysis)

\begin{tabular}{|c|c|c|c|c|}
\hline & (1) Netherlands & (2) Italy & (3) United Kingdom & (4) Ireland \\
\hline Age at migration & $\begin{array}{c}0.02^{*} \\
(0.01)\end{array}$ & $\begin{array}{l}-0.01 \\
(0.01)\end{array}$ & $\begin{array}{l}-0.01 \\
(0.01)\end{array}$ & $\begin{array}{l}-0.01 \\
(0.01)\end{array}$ \\
\hline \multicolumn{5}{|l|}{ Migration status (Employment-ref.): } \\
\hline Asylum & $\begin{array}{c}0.47 \\
(0.26)\end{array}$ & n.a. & $\begin{array}{c}0.62 \\
(0.34)\end{array}$ & $\begin{array}{c}0.40 \\
(0.27)\end{array}$ \\
\hline Family migration & $\begin{array}{c}0.13 \\
(0.21)\end{array}$ & $\begin{array}{c}0.11 \\
(0.14)\end{array}$ & $\begin{array}{c}0.10 \\
(0.24)\end{array}$ & $\begin{array}{c}0.16 \\
(0.13)\end{array}$ \\
\hline Other migration & $\begin{array}{l}-0.15 \\
(0.23)\end{array}$ & $\begin{array}{l}-0.50 \\
(0.28)\end{array}$ & $\begin{array}{c}0.01 \\
(0.21)\end{array}$ & $\begin{array}{l}-0.13 \\
(0.13)\end{array}$ \\
\hline \multicolumn{5}{|l|}{ Education level (ISCED 1-2-ref.): } \\
\hline ISCED 3-4 & $\begin{array}{c}0.15 \\
(0.19)\end{array}$ & $\begin{array}{c}0.24 \\
(0.13)\end{array}$ & $\begin{array}{c}0.62^{*} \\
(0.26)\end{array}$ & $\begin{array}{c}0.00 \\
(0.14)\end{array}$ \\
\hline ISCED 5-6 & $\begin{array}{c}0.03 \\
(0.14)\end{array}$ & $\begin{array}{c}0.25 \\
(0.18)\end{array}$ & $\begin{array}{l}0.42^{*} \\
(0.19)\end{array}$ & $\begin{array}{c}0.17 \\
(0.12)\end{array}$ \\
\hline \multicolumn{5}{|l|}{ Education (Recognized-ref.): } \\
\hline Host country education & $\begin{array}{c}0.03 \\
(0.19)\end{array}$ & $\begin{array}{c}0.04 \\
(0.29)\end{array}$ & $\begin{array}{l}-0.51^{*} \\
(0.22)\end{array}$ & $\begin{array}{c}0.58^{*} \\
(0.20)\end{array}$ \\
\hline Education not fully recognized & $\begin{array}{c}0.07 \\
(0.25)\end{array}$ & $\begin{array}{l}-0.31 \\
(0.38)\end{array}$ & $\begin{array}{c}0.41 \\
(0.50)\end{array}$ & $\begin{array}{c}0.97^{*} \\
(0.30)\end{array}$ \\
\hline No need for recognition & $\begin{array}{c}0.17 \\
(0.19)\end{array}$ & $\begin{array}{l}-0.49^{*} \\
(0.23)\end{array}$ & $\begin{array}{c}0.41 \\
(0.31)\end{array}$ & $\begin{array}{c}0.33 \\
(0.17)\end{array}$ \\
\hline Education not recognized & $\begin{array}{l}-0.10 \\
(0.19)\end{array}$ & $\begin{array}{l}-0.61^{*} \\
(0.26)\end{array}$ & $\begin{array}{c}0.05 \\
(0.39)\end{array}$ & $\begin{array}{c}0.12 \\
(0.19)\end{array}$ \\
\hline Language tuition & $\begin{array}{c}0.67^{*} \\
(0.16)\end{array}$ & $\begin{array}{c}0.11 \\
(0.17)\end{array}$ & $\begin{array}{l}0.61^{*} \\
(0.18)\end{array}$ & $\begin{array}{l}0.34^{*} \\
(0.12)\end{array}$ \\
\hline Labor market counseling & $\begin{array}{c}0.87^{*} \\
(0.13)\end{array}$ & $\begin{array}{l}-0.07 \\
(0.22)\end{array}$ & $\begin{array}{c}0.53^{*} \\
(0.19)\end{array}$ & $\begin{array}{l}1.08^{*} \\
(0.11)\end{array}$ \\
\hline$N$ & 881 & 1,379 & 942 & 1,169 \\
\hline
\end{tabular}

Note: Data are from EULFS 2008 ad hoc module on integration of migrants, author's calculations. The following variables are not shown but are included in the model: regional fixed effects, origin fixed effects, gender, year of migration, children under 3, permanent residence permit, naturalization. For complete results, consult supplementary Table A.3.

${ }^{*} \mathrm{p}<0.05$.

all countries in the subsample, except Italy. In most of the countries, the higher the level of education, the lower the propensity to pursue labor market counseling. The effects are substantial and statistically significant for the Netherlands and the United Kingdom. Furthermore, immigrants whose foreign education was recognized in the host country are more likely to receive labor market counseling in the Netherlands, Italy, and Ireland. In the United Kingdom, immigrants with host country education are more likely to receive labor market counseling than the rest. Immigrants who 
Table 2: Selected Predictors of Participation in Training (Results of the Probit Regression from the PSM Analysis)

\begin{tabular}{lcccc}
\hline & (1) Netherlands & $(2)$ Italy & (3) United Kingdom & (4) Ireland \\
\cline { 2 - 5 } Age at migration (years) & 0.01 & 0.01 & -0.00 & 0.01 \\
Migration status (Employment-ref.): & $(0.01)$ & $(0.01)$ & $(0.00)$ & $(0.01)$ \\
Asylum & & & & \\
& 0.02 & n.a. & $0.77^{*}$ & 0.29 \\
Family migration & $(0.25)$ & & $(0.24)$ & $(0.28)$ \\
& -0.00 & -0.19 & 0.16 & 0.09 \\
Other migration & $(0.19)$ & $(0.13)$ & $(0.16)$ & $(0.14)$ \\
& -0.09 & -0.08 & 0.10 & 0.07 \\
Educational level (ISCED 1-2-ref.): & $(0.21)$ & $(0.23)$ & $(0.14)$ & $(0.13)$ \\
ISCED 3-4 & & & & -0.04 \\
& $-0.57^{*}$ & 0.02 & -0.12 & $(0.14)$ \\
ISCED 5-6 & $(0.20)$ & $(0.12)$ & $(0.21)$ & -0.08 \\
& $-0.62^{*}$ & 0.07 & $-0.42^{*}$ & $(0.13)$ \\
Education (Recognized-ref.): & $(0.14)$ & $(0.16)$ & $(0.14)$ & $-0.48^{*}$ \\
Host country education & & & & $(0.21)$ \\
& $-0.87^{*}$ & $-0.55^{*}$ & $0.32^{*}$ & -0.02 \\
Education not fully recognized & $(0.17)$ & $(0.27)$ & $(0.14)$ & $(0.29)$ \\
& -0.27 & $-0.93^{*}$ & -0.15 & -0.31 \\
No need for recognition & $(0.22)$ & $(0.41)$ & $(0.48)$ & $(0.16)$ \\
Education not recognized & $-1.06^{*}$ & $-0.60^{*}$ & -0.44 & $-0.39^{*}$ \\
Labor market training & $(0.18)$ & $(0.20)$ & $(0.27)$ & $(0.18)$ \\
& $-0.86^{*}$ & $-0.86^{*}$ & -0.21 & $1.04^{*}$ \\
Language tuition & $(0.17)$ & $(0.22)$ & $(0.27)$ & $(0.11)$ \\
$N$ & $0.88^{*}$ & -0.06 & $0.63^{*}$ & 0.24 \\
& $(0.13)$ & $(0.22)$ & $(0.21)$ & 1,169 \\
\hline
\end{tabular}

Note: Data are from EULFS 2008 ad hoc module on integration of migrants, author's calculations. The following variables are not shown but are included in the model: regional fixed effects, origin fixed effects, gender, year of migration, children under 3, permanent residence permit, naturalization. For complete results, consult supplementary Table A.4.

${ }^{*} p<0.05$.

receive labor market counseling are more likely to report language problems in Ireland and the United Kingdom (see supplementary Table A.4).

On the basis of both probit regressions, we can conclude that immigrants who receive labor market counseling tend to be less educated and less proficient in the host country language - and hence overall somewhat more negatively selected for labor market success- than those who participate in labor market training. To the 
Table 3: Difference between Control and Treatment Groups in the Outcomes of Labor Market Training before and after Matching

\begin{tabular}{lccccc}
\hline & $\begin{array}{l}\text { (1) MIPEX 2007 score } \\
\text { Country }\end{array}$ & \multicolumn{2}{c}{ (2) Unemployment } & \multicolumn{2}{c}{ (3) ISEI } \\
& $\begin{array}{c}\text { (Labor Market } \\
\text { Mobility / Access / } \\
\text { Targeted Support) }\end{array}$ & $\begin{array}{c}\text { Unmatched: } \\
\text { Difference }\end{array}$ & $\begin{array}{c}\text { Matched: } \\
\text { Effect (ATT) }\end{array}$ & $\begin{array}{c}\text { Unmatched: } \\
\text { Difference }\end{array}$ & $\begin{array}{c}\text { Matched: } \\
\text { Effect (ATT) }\end{array}$ \\
\hline Netherlands & $85 / 71 / 75$ & 0.05 & 0.06 & $-3.35^{*}$ & -0.82 \\
& & $(0.03)$ & $(0.03)$ & $(1.67)$ & $(1.81)$ \\
Italy & $69 / 50 / 25$ & 0.02 & 0.01 & $4.44^{*}$ & $4.05^{*}$ \\
United Kingdom & $55 / 43 / 25$ & $(0.04)$ & $(0.04)$ & $(1.39)$ & $(1.43)$ \\
& & 0.03 & 0.00 & -4.25 & -3.36 \\
Ireland & $42 / 21 / 25$ & $(0.05)$ & $(0.06)$ & $(3.03)$ & $(3.34)$ \\
& & 0.00 & -0.04 & 2.04 & 2.35 \\
& & $(0.03)$ & $(0.03)$ & $(1.31)$ & $(1.32)$ \\
\hline
\end{tabular}

Note: Data from EULFS 2008 ad hoc module on integration of migrants, author's calculations. Standard errors in the matched samples are bootstrapped with 500 repetitions each to account for the additional variability introduced by estimating the propensity score and by the matching process itself.

$* p<0.05$.

extent that employers are aware of these facts, they might perceive labor market counseling less favorably than labor market training.

\section{Effectiveness of Immigrant Integration Programs}

This section examines whether labor market training and counseling are effective: that is, whether participation in integration measures immediately after immigration leads to more favorable outcomes several years later compared to nonparticipation. Table 3 presents the results of the second step of the PSM for labor market training participation for both unmatched and matched samples, and Table 4 does the same for labor market counseling. Mean differences (and standard errors) between those who participated in training and those who did not are shown in the columns featuring the unmatched sample. The ATT and bootstrapped standard errors are found in the columns with the matched sample data. ATTs stem from the analyses based on several matching algorithms. We compared the results produced by matching the nearest five neighbors, by imposing a caliper (0.05), and by using Epachenikov and Gaussian kernel matching. For each country and each outcome, we selected the results from the algorithm that yielded the largest reduction of the mean standardized bias and the best balancing of covariates. ${ }^{12}$

Because both participants and non-participants of labor market training might differ in a number of characteristics that are also related to the labor market outcomes of interest, comparing the unmatched and matched samples offers yet another indication of selectivity in the treatment group. What do we learn from this 
Table 4: Difference between Control and Treatment Groups in the Outcomes of Labor Market Counseling before and after Matching

\begin{tabular}{lccccc}
\hline & $\begin{array}{l}\text { (1) MIPEX 2007 score } \\
\text { Country }\end{array}$ & \multicolumn{2}{c}{ (2) Unemployment } & \multicolumn{2}{c}{ (3) ISEI } \\
& $\begin{array}{c}\text { (Labor Market } \\
\text { Mobility / Access / } \\
\text { Targeted Support) }\end{array}$ & $\begin{array}{c}\text { Unmatched: } \\
\text { Difference }\end{array}$ & $\begin{array}{c}\text { Matched: } \\
\text { Effect (ATT) }\end{array}$ & $\begin{array}{c}\text { Unmatched: } \\
\text { Difference }\end{array}$ & $\begin{array}{c}\text { Matched: } \\
\text { Effect (ATT) }\end{array}$ \\
\hline Netherlands & $85 / 71 / 75$ & 0.02 & 0.02 & $-5.66^{*}$ & -1.41 \\
& & $(0.02)$ & $(0.03)$ & $(1.50)$ & $(1.36)$ \\
Italy & $69 / 50 / 25$ & 0.01 & 0.02 & 0.43 & -0.18 \\
United Kingdom & $55 / 43 / 25$ & $(0.03)$ & $(0.03)$ & $(1.21)$ & $(1.27)$ \\
& & $0.10^{*}$ & -0.01 & $-4.98^{*}$ & 0.72 \\
Ireland & $42 / 21 / 25$ & $(0.03)$ & $(0.04)$ & $(1.81)$ & $(1.78)$ \\
& & $0.11^{*}$ & $0.12^{*}$ & 1.76 & 0.67 \\
& & $(0.03)$ & $(0.04)$ & $(1.50)$ & $(1.69)$ \\
\hline
\end{tabular}

Note: Data are from EULFS 2008 ad hoc module on integration of migrants, author's calculations. Standard errors in the matched samples are bootstrapped with 500 repetitions each to account for the additional variability introduced by estimating the propensity score and by the matching process itself.

$* p<0.05$.

comparison? Taking into account the non-random assignment of immigrants to the control and treatment groups, we largely observe no difference between both groups with regard to training participation (see Table 3). Only in the Netherlands do immigrants who acquired labor market training have a significantly lower occupational status. In Italy, on the contrary, immigrants have an advantageous occupational status if they participated in training.

The disadvantages are substantially more pronounced among immigrants who participated in labor market counseling (see Table 4). Immigrants who received counseling have significantly higher unemployment propensities in Ireland and the United Kingdom and significantly lower occupational status in the Netherlands and the United Kingdom. Comparing the two outcomes again leads us to conclude that "negative" selection is more pronounced among participants in labor market counseling, which is in line with the results of the previous section.

The results based on the matched samples show that neither labor market training nor labor market counseling is associated with better labor market outcomes across the bulk of the analyzed countries. Italy is the only country in the sample where training seems to increase the occupational status of immigrants' jobs. There, the occupational status premium of immigrants who participated in labor market training compared to those who should have participated according to their observed characteristics but did not do so is slightly above 4 ISEI points. In Ireland, labor market counseling is associated with greater difficulties in finding employment: the employment penalty of immigrants who received labor market counseling compared to their statistical twins (who should have received it but did not) is 12 percent. The result for Italy is the only positive, statistically significant, 
albeit rather weak, effect of training that we are able to detect in our data, which seems to support the productivity skills argument found in the literature. The result for Ireland might indicate the stigmatization or negative selection hypotheses. The rest of the ATT effects are neither particularly strong nor statistically significant, which suggests that the productivity-enhancing character of training or counseling is not driving the effects. If anything, we might witness forces that work in opposite directions and hence cancel each other out: for example, resource accumulation among individuals who are negatively selected with regard to their unobserved characteristics.

Finally, the question arises whether patterns of effectiveness in integration policies correspond to the countries' policy intentions. With a sample of four countries, only a tentative qualitative assessment is possible; we cannot make any statistics-based conclusions about the association between policy intentions and effects. If anything, we can see that the negative effect of labor market counseling is substantial only in Ireland, the country with the lowest MIPEX in our sample. Yet, we observe that labor market training has positive effects only in Italy, which occupies a midfield position with regard to policy intentions. Thus, we cannot draw any meaningful overall conclusions about the relationship between policies' intentions and their effectiveness at this point.

\section{Summary and Discussion}

Previous research has highlighted the importance of host countries' immigration and integration policies for immigrants' successful labor market integration (Reitz 2002). This study builds on both multilevel studies on the role of integration policy in immigrants' labor market integration and on evaluation research focusing on the causal effects of specific integration measures. It unifies the strengths of both approaches by combining a large-scale assessment of the coverage of selected immigrant integration measures - training and labor market counseling-in a large number of European countries with detailed, in-depth analyses of the effectiveness of such tools in a selection of immigrant destinations.

Following our research questions related to the comprehensiveness and effectiveness of integration policies, several facts come to light. First, we are able to show that the actual provision of recent immigrants with labor market training does not seem to entirely correspond to the policy intentions (as captured by MIPEX 2007), whereas labor market counseling more closely reflects the policies' proclaimed aims. Second, we find that labor market training and counseling are largely ineffective in the selection of countries we examined. Training only had a significant positive effect on the occupational status of immigrants' jobs in Italy, whereas it had a negative effect on the chances of entering employment in Ireland. We credit the lack of positive effects of labor market counseling to allegedly stronger negative signals associated with the utilization of job search assistance (compared to training). These signals might be attributable to a more pronounced negative selection on observables: for example, education and a possible adverse selection on unobservables among recipients of labor market counseling. We further suspect that a-by and large-lack of positive labor market returns on training participation is due to 
ineffective training or benefits of training being offset by a particularly unfavorable selection of program participants. ${ }^{13}$

Our results ascertain that policy intentions are not automatically translated into successfully implemented policies in terms of comprehensive coverage, nor are they necessarily effective and lead to more advantageous labor market positions for immigrants. This study's message is thus that comprehensive coverage of immigrant integration programs, or even their compulsory character, do not guarantee a more favorable labor market integration of immigrants. A successful integration policy is an effective one; that is, a policy that-despite a possibly negative selection of integration programs' participants-helps participants to acquire productive skills and host country-specific competencies, provides them with useful information for navigating the labor market, and endows them with signals that are adequately perceived by employers.

Altogether, the study's contributions are threefold. Our main policy-related contribution was to report on the lack of labor market benefits associated with labor market training participation and labor market counseling across a number of European countries for which there was little comparable previous research. In accordance with the existing evaluation research, we were not able to present conclusive evidence of effective labor market training and counseling in the Netherlands, Ireland, or the United Kingdom. On the theoretical level, the study provided weak support for the productivity skills argument, emphasizing instead the validity of the signaling and selection perspectives. Methodologically, the study attempted to break new ground synthesizing sociological and economic approaches to arrive at a more comprehensive understanding of policy effectiveness.

This study also has some limitations. Although the EULFS data allow us to conduct a large-scale overview, their cross-sectional nature hampers any firm causal claims. Therefore, future research has to rely on panel data sets from various countries. However, these are rare and plagued by problems of selective non-response, attrition, and comparability. Furthermore, there is an urgent need to extend the list of policy tools and labor market outcomes to be scrutinized. With regard to the former, language tuition and recognition of educational credentials are the most obvious candidates. With regard to the latter, the list of the labor market outcomes can be extended to include the propensity to work in nonstandard jobs, self-employment, wages, and more dynamic outcomes, such as speed of entry to first employment in the host country, job loss, and job re-entry chances. Furthermore, research should pay attention to more subjective dimensions of integration, such as life satisfaction and quality of life, to more comprehensively assess immigrants' integration into the host society. Comparing immigrants to the native-born population would add another dimension to the analysis and help in understanding whether labor market integration measures operate similarly across various population groups. The analyses of the effect heterogeneity should be further extended to capture both genders, various educational groups, and immigrants' settlement status. Finally, future research should try to include the demand side of the labor market, focusing on employers' assessments of signals associated with immigrants' integration efforts. 


\section{Notes}

1 We use the 2007 MIPEX because our data are from the 2008 European Union Labour Force Survey.

2 Education as a separate dimension of MIPEX is not available for 2007 but has appeared in MIPEX versions since 2010.

3 Within each topic, a number of subtopics are evaluated: for example, access to general and targeted support within the labor market mobility theme.

4 To estimate the effects of immigrants' integration measures, we need sufficient sample sizes of recent immigrants who have resided in the host country more than 2 years (because the question about participation in integration measures pertains to the first 2 years after migration) but less than 10 years. Excluding immigrants with less than 2 years since migration reduced the sample sizes in each country. To ensure reliable results for the propensity score matching analysis, we test our hypothesis using the subset of countries with a sample size of at least 750 cases. The country selection is also based on the satisfactory performance of the propensity score matching (see later).

5 Overall, a satisfactory number of cases to be effectively used for the PSM can be reported for the four countries.

6 When we use the term third-country immigrants we refer to all immigrants apart from the reference category.

7 This variable was approximated based on the information pertaining to the number of children in various age groups when the survey was conducted and the variable Years Since Migration.

8 Note that the results do not change substantially when these variables are dropped from the analyses.

9 This is described by the MIPEX group on its website (http://old.mipex.eu).

10 Luxembourg and Portugal are excluded from these analyses because of the data issues.

11 Results presented in Tables 1 and 2 are the first step of PSM with unemployment propensity being an outcome.

12 Supplementary Tables A.5-A.8 assess quality of the matched samples for each treatment and each outcome variable. The mean standardized bias after matching for the bestperforming matching algorithm is substantially below 5 in all four countries, which is seen as sufficient to balance the differences between the control and the treatment groups (Caliendo and Kopeinig 2008).

13 The current study design does not allow differentiation between possible mechanisms. Additional research is needed in this regard.

\section{References}

Aldashev, A., S. Thomsen, and T. Walter. 2010. "Short-Term Training Programs for Immigrants: Do Effects Differ from Natives and Why?" Discussion Paper 10-021, ZEW.

Aleksynska, M., and A. Tritah. 2013. “Occupation-Education Mismatch of Immigrant Workers in Europe: Context and Policies." Economics of Education Review 36:229-44. http://dx.doi.org/10.1016/j.econedurev.2013.06.001.

Åslund, O., and P. Johansson. 2006. “Virtues of SIN — Effects of an Immigrant Workplace Introduction Program." Working Paper 7, IFAU. 
Becker, G. 1964. Human Capital: A Theoretical and Empirical Analysis with Special References to Education. New York: Columbia University Press.

Bilgili, Ö., T. Huddelston, A. and Joki. 2015. The Dynamics between Integration Policies and Outcomes: Synthesis of the Literature. http://www .migpolgroup.com/portfolio/ the-dynamics-between-integration-policies-and-outcomes-a-synthesis-ofthe-literature.

Borjas, G. 1990. Friends or Strangers: The Impact of Immigration on the US Economy. New York: Basic Books.

Borjas, G. 1994. “The Economics of Immigration." Journal of Economic Literature 32(4):16671717.

Brand, J., and C. Halaby. 2006. "Regression and Matching Estimates of the Effects of Elite College Attendance on Educational and Career Attendance." Social Science Research 35(3):749-70. http://dx.doi.org/10.1016/j.ssresearch.2005.06.006.

Butschek, S., and T. Walter. 2014. “What Active Labour Market Programmes Work for Immigrants in Europe? A Meta-Analysis of the Evaluation Literature." IZA Journal of Migration 3:48. http://dx.doi.org/10.1186/s40176-014-0023-6.

Cain, G. 1986. “The Economic Analysis of Labor Market Discrimination: A Survey.” Pp. 693-781 in Handbook of Labor Economics, edited by O. Ashenfelter and R. Layard. Vol. I., Amsterdam: Elsevier.

Caliendo, M., and S. Kopeinig. 2008. "Some Practical Guidance for the Implementation of Propensity Score Matching." Journal of Economic Surveys 22:31-72. http: //dx . doi .org/ $10.1111 / j .1467-6419.2007 .00527 . x$.

Cebolla-Boado, H., and C. Finotelli. 2011. "Integration beyond Models: An Empirical Outlook to the Impact of Integration Models." Estudios/Working Papers Centro de Estudios Avanzados en Ciencias Sociales 264: 1-19.

Cebolla-Boado, H., and C. Finotelli. 2015. "Is There a North-South Divide in Integration Outcomes? A Comparison of the Integration Outcomes of Immigrants in Southern and Northern Europe." European Journal of Population 31(1):77-102. http://dx. doi . org/10 . 1007/s10680-014-9327-8.

Chiswick, B. 1978. "The Effect of Americanization on the Earnings of Foreign-Born Men." Journal of Political Economy 86(5):897-921. http: //dx . doi .org/10.1086/260717.

Chiswick, B. 1979. "The Economic Progress of Immigrants: Some Apparently Universal Patterns." Pp. 357-399 in Contemporary Economic Problems, edited by W. Fellner. Washington, DC: American Enterprise Institute for Public Policy Research.

Clausen, J., E. Heinesen, H. Hummelgaard, L. Husted, and M. Rosholm. 2009. "The Effect of Integration Policies on the Time until Regular Employment of Newly Arrived Immigrants: Evidence from Denmark." Labour Economics 16(4):109-417. http://dx.doi.org/10. 1016/j.labeco.2008.12.006.

Cohen, S., and Z. Eckstein. 2008. "Labour Mobility of Immigrants: Training, Experience, Language and Opportunities." International Economic Review 49(3):837-72. http://dx . doi.org/10.1111/j.1468-2354.2008.00499.x.

Cohen-Goldner, S., and Z. Eckstein. 2010. “Estimating the Return to Training and Occupational Experience: The Case of Female Immigrants." Journal of Econometrics 156(1):86-105. http://dx.doi.org/10.1016/j.jeconom.2009.09.009.

Corrigan, O. 2015. "Conditionality of Legal Status and Immigrant Occupational Attainment in Western Europe." Policy and Politics 43(2):181-202. http://dx.doi.org/10.1332/ 030557314 X13908300629975. 
Fleischmann, F., and J. Dronkers. 2010. "Unemployment among Immigrants in European Labour Markets: an Analysis of Origin and Destination Effects." Work, Employment and Society 24(2):337-54. http://dx . doi . org/10.1177/0950017010362153.

Friedberg, R. 2000. "You Can't Take It with You? Immigrant Assimilation and the Portability of Human Capital." Journal of Labor Economics 18(2):221-51. http://dx.doi.org/10. $1086 / 209957$.

Ganzeboom, H. B. G., P. de Graaf, and D.J. Treiman. 1992. "A Standard International Socio-Economic Index of Occupational Status." Social Science Research 21(1):1-56. http: //dx.doi.org/10.1016/0049-089X (92) 90017-B.

Goodman, S. 2010. “Integration Requirements for Integration's Sake? Identifying, Categorising and Comparing Civic Integration Policies." Journal of Ethnic and Migration Studies 36(5):753-72. http://dx.doi.org/10.1080/13691831003764300.

Hadjar, A., and S. Backes. 2013. "Migration Background and Subjective Well-Being: A Multilevel Analysis Based on the European Social Survey." Comparative Sociology 12(5):645-76. http://dx.doi.org/10.1163/15691330-12341279.

Harding, D. J. 2003. “Counterfactual Models of Neighborhood Effects: The Effect of Neighborhood Poverty on Dropping Out and Teenage Pregnancy." American Journal of Sociology 109(3):676-719. http://dx .doi.org/10.1086/379217.

Huddleston, T., J. Niessen, E. Chaoimh, and E. White. 2011. Migrant Integration Policy Index III. Brussels: British Council and Migration Policy Group.

Janoski, T. 2010. The Ironies of Citizenship: Naturalization and Integration in Industrialised Countries. New York: Cambridge University Press. http://dx.doi.org/10.1017/ CB09780511779206.

Kalter, F., and I. Kogan. 2014. "Migrant Networks and Labor Market Integration of Immigrants from the Former Soviet Union in Germany." Social Forces 92(4):1435-56. http://dx.doi.org/10.1093/sf/sot155.

Kogan, I. 2006. "Labor Markets and Economic Incorporation among Recent Immigrants in Europe." Social Forces 85(2):697-721. http: //dx. doi .org/10.1353/sof . 2007. 0014.

Kogan, I. 2007. Working through Barriers: Host Country Institutions and Immigrant Labour Market Performance in Europe. Dordrecht, Netherlands: Springer.

Kogan, I. 2012. "Potenziale nutzen! Determinanten und Konsequenzen der Anerkennung von Bildungsabschlüssen bei Zuwanderern aus der ehemaligen Sowjetunion in Deutschland." Kölner Zeitschrift für Soziologie und Sozialpsychologie 64(1):67-89. http://dx . doi . org/10 . 1007/s11577-012-0157-6.

Kogan, I., F. Kalter, E. Liebau, and Y. Cohen. 2011. “Individual Resources and Structural Constraints in Immigrants Labour Market Integration. " Pp. 75-100 in A Life-Course Perspective on Migration and Integration, edited by M. Wingens, M. Windzio, H. de Valk, and C. Aybek. Dordrecht, Netherlands: Springer. http://dx.doi .org/10.1007/978-94-007-1545-5_ 4.

Kogan, I., T. Matković, and M. Gebel. 2013. “Helpful Friends? Personal Contacts and Job Entry among Youths in Transformation Societies." International Journal of Comparative Sociology 54(4):277-97. http://dx. doi .org/10.1177/0020715213509256.

Koopmans, R., I. Michalowski, and S. Waibel. 2012. "Citizenship Rights for Immigrants: National Political Processes and Cross-National Convergence in Western Europe, 1980-2008." American Journal of Sociology 117(4):1202-45. http://dx . doi . org/10 . 1086/662707.

Mincer, J. 1974. Schooling, Experience, and Earnings. New York: National Bureau of Economic Research. 
Morgan, S., and D. Harding. 2006. "Matching Estimators of Causal Effects Prospects and Pitfalls in Theory and Practice." Sociological Methods and Research 35(1):3-60. http: //dx.doi.org/10.1177/0049124106289164.

Niessen, J., T. Huddleston and L. Citron. 2007. Migrant Integration Policy Index. Brussels: British Council and Migration Policy Group.

Pichler, F. 2011. "Success on European Labor Markets: A Cross-National Comparison of Attainment between Immigrant and Majority Populations." International Migration Review 45(4):938-78. http://dx.doi.org/10.1111/j.1747-7379.2011.00873.x.

Portes, A., and R. Rumbaut. 2001. Legacies. Berkeley: University of California Press.

Reitz, J. 2002. "Host Societies and the Reception of Immigrants: Research Themes, Emerging Theories and Methodological Issues." International Migration Review 35(4):1005-19. http: //dx.doi.org/10.1111/j.1747-7379.2002.tb00115.x.

Reitz, J. 2003. "Host Societies and the Reception of Immigrants: Research Themes, Emerging Theories, and Methodological Issues." Pp. 1-20 in Host Societies and the Reception of Immigrants, edited by J. Reitz. San Diego: University of California Press.

Rinne, U. 2013. "The Evaluation of Immigration Policies." Pp. 530-551 in International Handbook on the Economics of Migration, edited by A. Constant and K. Zimmermann. Cheltenham, UK: Edward Elgar. http://dx.doi.org/10.4337/9781782546078.00038.

Rosenbaum, P. R., and D. B. Rubin. 1985. "Constructing a Control Group Using Multivariate Matched Sampling Methods That Incorporate the Propensity Score." The American Statistician 39:33-38.

Ruhs, M. 2011. “Openness, Skills and Rights: An Empirical Analysis of Labor Immigration Programmes in 46 High and Middle Income Countries." Working Paper 88: Centre on Migration, Policy and Society.

Sarvimäki, M., and K. Hämäläinen. 2011. "Assimilating Immigrants: The Impact of an Integration Program." Discussion Paper 2011-015, NORFACE.

Spence, M. 1973. “Job Market Signaling." The Quarterly Journal of Economics 87(3):355-74. http://dx.doi.org/10.2307/1882010.

Stiglitz, J. 1975. "The Theory of 'Screening', Education, and the Distribution of Income." The American Economic Review 65(3):283-300.

Thomsen, S., and T. Walter. 2010. “Temporary Extra Jobs for Immigrants: Merging Lane to Employment or Dead End Road in Welfare?" Labour: Review of Labour Economics and Industrial Relations, 24 (Special Issue):114-40.

Thomsen, S., T. Walter, and A. Aldashev. 2013. "Short-Term Training Programs for Immigrants in the German Welfare System: Do Effects Differ from Natives and Why?" IZA Journal of Migration 2:24. http://dx. doi .org/10.1186/2193-9039-2-24.

Van Tubergen, F., I. Maas, and H. Flap. 2004. "The Economic Incorporation of Immigrants in 18 Western Societies: Origin, Destination, and Community Effects." American Sociological Review 69(5):704-27. http://dx.doi.org/10.1177/000312240406900505.

Wiley, N. 1970. "The Ethnic Mobility Trap and Stratification Theory." Pp. 397-408 in The Study of Society: An Integrated Anthology, edited by P. Rose. New York: Random House.

Winship, C., and S. L. Morgan. 1999. "The Estimation of Causal Effects from Observational Data." Annual Review of Sociology 25:659-706. http://dx.doi .org/10.1146/annurev. soc.25.1.659. 
Acknowledgements: Earlier versions of the article were presented at ECSR Spring School, Collegio Carlo Alberto, Turin, March 23-27, 2015; Nuffield College Sociology Seminar, University of Oxford, June 3, 2015; and Annual BAGGS Conference on Inequality, University of Bamberg, September 29-30, 2015. We thank the participants for their valuable comments and suggestions.

Irena Kogan: University of Mannheim. E-mail: ikogan@mail.uni-mannheim.de. 